\title{
Digitality: A reality check
}

\author{
Jonathan P. Bowen \\ Emeritus Professor of Computing \\ School of Engineering \\ London South Bank University \\ London, UK \\ http://www.jpbowen.com \\ jonathan.bowen@lsbu.ac.uk
}

\author{
Tula Giannini \\ Professor of Information \\ School of Information \\ Pratt Institute \\ New York, USA \\ https://sites.google.com/view/tgiannini/ \\ giannini@pratt.edu
}

\begin{abstract}
The condition of digitality and the associated concept of digitalism are increasingly important today. Our ever-more digital societal context means that many are experiencing a digital life where reality and digitality blur in their distinction in many people's digital lives. This paper considers these aspects with respect to digital culture, especially in the context of heritage and museums. In particular, we look at developments since a previous 2014 paper by the authors and speculate on possible future developments. We focus especially on the reality check provided by the Covid-19 pandemic, that has accelerated societal digitality.
\end{abstract}

Digitalism. Digitality. Digitalisation. Digital culture. Digital life. Digital heritage. Covid-19.

\section{BACKGROUND}

\section{More than human (by T. Giannini)}

\author{
When Internet life \\ becomes more than real \\ Artificial life becomes more than human \\ Robots make things \\ Birds still sing \\ Humans hide \\ No free ride \\ Lock 'em down \\ Going to drown \\ In tears and fears \\ How many years \\ Can this last \\ Present to past \\ Let's ask Turing and da Vinci - \\ How can we survive \\ keeping love alive $\bigcirc$
}

This paper follows on from a previous paper on "digitalism" and "digitality" as its associated state is sometimes known, concerning the increase of digital culture becoming a modern reality (Bowen \& Giannini 2014).

Historically, Charles Babbage (1791-1871) was the first to originate the idea of a programmable digital computer with his design for a mechanical Analytical Engine (Dasgupta 2014). His associate Ada Lovelace (1815-1852) is believed to be the first person to recognise that such a device could be used for more than purely calculational applications (Hollings et al. 2018; Padua 2015). A century later,
Alan Turing (1912-1954) is widely acknowledged to be the first to formulate a mathematical abstract model for a computational device (Turing 1936), now known as a Turing Machine (Copeland et al. 2017).

More recently, in the mid-1990s, museums started to realise the opportunities provided by digital culture on the World Wide Web (Bowen 1995a; 1995b; Gaia et al. 2020). Online provision by museums has increased, with collaboration between museums and other heritage organisations enabling more and more synergistic collections of material online (Giannini \& Bowen 2014).

In 1996, Wired magazine, perhaps rashly, produced a book called Reality Check, providing predictions for the future technological development by year (Wieners \& Pescovitz 1996). 2014 was given as the year when online advertising eclipses TV commercials. Certainly, Internet giants such as Facebook now make huge amounts of money from targeted online advertising (Moore \& Tambini 2018). However, the lack of regulation has created problems such as fake news (Vaidhyanathan 2018), as witnessed by the storming of the Capitol in Washington D.C. on 6 January 2021 for example.

For 2016, the first large public virtual library was predicted. The not-for-profit Internet Archive (https://archive.org), originally established in 1996, the same year that the Reality Check book was published, now provides access to many books online that can be viewed online within copyright 
constraints. As a small organisation, the Internet Archive has been able to develop its digital resources more quickly that other longerestablished organisations, including libraries (Ovenden 2020). The commercial Google Books website (https://books.google.com), launched by Google in 2004, provides access to many scanned books provided by a number of major libraries, again limited by copyright restrictions. 2019 included self-driving vehicles, quite well predicted for their existence if not widespread use. Humans on Mars in 2020 was less well predicted. One thing that was not predicted was a pandemic and the associated vaccine developments.

For the future, a Star Trek style "tricorder" for 2023, detecting a patient's vital signs and internal injuries externally with a small device, is not quite there, but we do mostly now have smartphones, with the potential ability to do medical monitoring for those that wish or need it. With the increasingly existentially worrying climate catastrophe, the predicting of more than $50 \%$ driving electric cars by 2034 is hopefully now likely in some forward-looking countries. All these advances, whether achieved or not, are highly dependent on developments in digital technology. Computer science researchers are increasingly interested in modelling systems involving humans, the physical world, and digital systems, with all the complexity that this involves in designing software for such systems, dubbed Human-Cyber-Physical Systems (Liu et al. 2020).

\section{DIGITALISM AND DIGITALITY}

In this paper, we consider condition of digitality (Franklin 2015; Hasson 2019; 2020) and the ideology of digitalism, encompassing the concept that everything can be explained in digital terms (Jandrić et al. 2018; Peters \& Besley 2019), in a cultural and heritage setting, especially concerning museums, (Giannini \& Bowen 2019a, 2019b, 2019c). There has been consideration of the mix of digitality and reality in a heritage context (Brusaporci 2018).

Virtual Reality (VR) is a simulated experience of a digital world. The term "virtuality" is sometimes used in describing such worlds. Augmented Reality (AR) is an interactive experience with the real world superimposed with additional computer-generated information, often visual but potentially including audio and other senses as well (Peddie 2017; Geroimenko 2019). Mixed Reality (MR) is the merging of the real and virtual worlds with physical and digital objects merged, and real-time interaction possible (loannides et al. 2017). This is a hybrid version of VR and reality. All these developments contribute to digitality in terms of $3 \mathrm{D}$ interaction.
Digitality does not have to depend on 3D worlds. Humans are highly adaptable to digital technology and can interact in many ways. Witness the wideranging types of content available on smartphones and tablets, often enabling creativity not previously possible (Berry 2017). David Hockney has used painting apps productively in his art practice, always willing to adapt to new approaches, for example using both the Apple iPhone and iPad (https://www.hockney.com/works/digital).

The pervasion of digitality influences many cultural aspects, such as (especially interactive) art (King 2015; Chau 2017; Seevinck 2017; Ravetto-Biagioli 2019), performance (Whatley et al. 2018), and even clothing through smart textiles (Schneegass \& Amft 2017). Museums provide experiences that have increasingly digital facets that require new areas of design expertise (Vereeren et al. 2018). As digitality matures, preservation of older content becomes more important, even at a personal level (Bowen 2017; Mezaris et al. 2018). Most recently, digitality has affected many people's lives greater than expected due to the Covid-19 pandemic.

\section{THE DIGITAL FRONTIER}

\subsection{Navigating the Covid Forces of Change}

While "big tech" and "big box" corporations have profited immensely from the massive expansion of digitality in everyday life due to the Covid pandemic, other sectors of society have been devastated and left in chaos and uncertainty. In particular, the cultural life of our great urban centres embodied in their museums, libraries, archives, and iconic universities. have experienced severe disruption. However, Covid was not the only powerful force at play as it converged with social unrest and protest and the trending advances in computing, especially Artificial Intelligence or Al (Bowen et al. 2020), and perhaps most significantly, in human digital behaviour as we witnessed human activity being dominated by digital media, with individuals average screen-time about 13 hours per day. Thus, even before Covid, there was an unrelenting expansion of the digitisation of life itself (Florida \& Seman 2020):

\footnotetext{
"Based on our analysis of creative occupations, we estimate losses of more than 2.3 million jobs and $\$ 74$ billion in average monthly earnings for the creative occupations. These losses represent $30 \%$ of all creative occupations and $15 \%$ of total average monthly wages. Again, creative occupations in the fine and performing arts - which include the visual arts, music, theatre, and dance - will be disproportionally affected, representing roughly a third of wage employment losses."
}

It seemed somewhat surprising when in May 2020 the University of Florida (UF) announced its plans 
for digital transformation, being the first university to adopt $\mathrm{Al}$ across all disciplines, programs and curricula, acquiring the advanced NVIDIA DGX A100 system to support their Al initiative. UF's President, Kent Fuchs, has stated (Wise 2020):

\begin{abstract}
"Artificial intelligence is poised to transform the way we all work with information, helping us address challenges and make discoveries that once seemed unattainable" ... "By immersing this powerful technology in the curriculum across UF, we are positioning Florida as a global leader in a technological revolution that - similar to the smartphone - will transform the way we live, work and interact with the world around us."
\end{abstract}

Thus in the midst of the worst pandemic in a hundred years, UF looked to Al as its answer to the future - a kind of get out of jail free card from pandemic lockdowns giving little consideration to digital states of being in urban centres with highrise apartments looking more prisons-like by the day (Wainwright 2019).

\subsection{Will City Life be More Imaginary Than Real?}

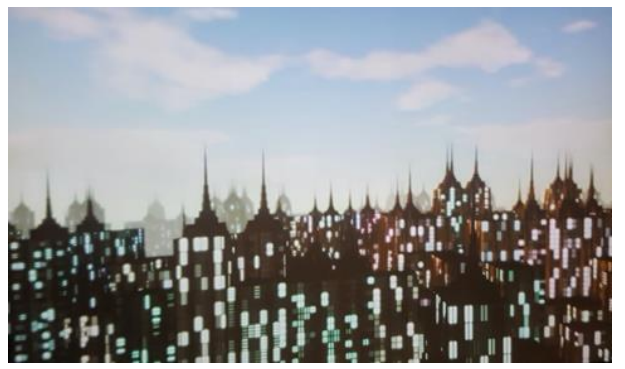

Figure 1: Interactive digital installation by artist curator, Michel Takeo Magruder from the July 2019 exhibition Imaginary Cities at the British Library of a virtual reality cityscape of New York City that responded to daily visitor data collected onsite. (Photo by T. Giannini.)

Looking out of New York City apartment windows, the notion of "imaginary cities" (Figure 1) expresses the state of virtual life encroaching on reality as artificial imagination crowds out physical space.

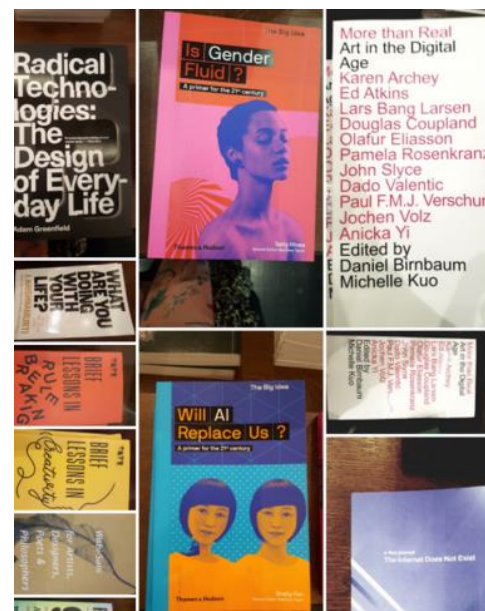

Figure 2: Books on display at the Barbican, London for the Exhibition, More than Human. (Photo by T. Giannini.)
Covid forces us to make choices and answer questions that suddenly seem pressing rather than speculative. What will life look like post Covid - how will we rebuild, or will we take new paths and form new identities? Books on display at the Barbican Museum during the exhibition Al More that Human (see Figure 2) appear to be asking such questions.

\subsection{What is Behind the Screen?}

Dorothy, the Scarecrow, the Tin Man, the Lion and Toto her dog return to $\mathrm{Oz}$ with the broomstick of the Wicked Witch of the West. They are immediately intimidated by The Wizard's loud scary voice in the dark with flames blasting. Toto runs to the noise and pulls back the curtain on what is a fake wizard running a light show - a moment symbolic of the plasticity of reality - can we believe our eyes? (Lewis 2007). As we retreat from observing physical reality and nature, we rely on our screens to tell us what is real. How can we see behind "the curtain" of what is artificial life when what we see is the superficial, we cannot see behind the curtain and who is controlling what is on the screen?

From 2018, most people have been spending more than 13 hours per day of screen time and since Covid this number is increasing. Given the expanding nature of our digital time and space, our existence is merging at the intersection of physical and virtual states of being. According to Statistica, $80 \%$ of Internet users have a YouTube account, second in popularity on to only Facebook. With the rapid rise of Zoom since Covid the is a surge of users creating their own YouTube content including ads, video podcasting with platform networking during 2020 is set to earn $\$ 4.34$ billion, up $26.5 \%$ more than 2019 (Statistica 2020).

Another significant trend accelerated by Covid is the huge spike in audio books (Nawotka 2020). The pandemic has seen a rapid increase in audiobook sales lead by Amazon Audible that, combined with general adoption of video, continues the trend away from text domination which is further reinforced when Covid caused a large-scale shift from onsite to online teaching and learning. With this intensified relationship between humans and digital media replacing reading, neuroscientists are studying how this might be altering the brain's neural networks and human language abilities (Lorte 2020).

With the lion's share of information and media use taking place on digital platforms, the traditional infrastructure supporting books, publishers, distributors, printers, stores, etc., is in chaos and might be on the verge of collapse. The means of production is now in the hands of both big tech and individuals using the latest software to produce using a range of media from videos, film and music podcasts. Publishing finds itself in an expanding 
landscape of information and entertainment, one of connected and networked media, in which the individual can publish whenever and wherever they wish, in the media of their choice especially as open-source publication sites proliferate. Print media could become a type of niche publication. Publishers of books, newspapers, and magazines are strategising about how to make digital publications fee based (Rajan 2020).

\subsection{Are Universities Avoiding Arts/Humanities?}

In the current digital frenzy taking hold across virtually all sectors of society, the message to students is that study in a STEM (Science, Technology, Engineering, and Mathematics) discipline will be mandatory for career success. Education is viewing computing, engineering and $\mathrm{Al}$ as the one stop shop for students, while the arts and humanities are being sidelined as impractical, lacking professional identity, and not worth the cost of the education. Does this foretell our move from being Athenians to Spartans? It seems that students have taken on this mantra and feel that without mastering technology and Al they will be left behind, when in fact, as Al and Machine Learning (ML) advance, those skills now hailed as critical will be easily carried-out by Al. Whereas, critical thinking, interpretation, creativity and intuition, etc., might become the very abilities humans will need to survive, and we note technology has no emotions and no feelings.

Considering education, we see that the discipline and the subject du jour is computer science and engineering, digital technology, $\mathrm{Al}$, and machine learning - and that computational tools are focusing on data collection, analytics, visualisation, and artificial life, where robots simulate being human and humans emulate robots. Humans are using digital tools and Al which they see can enhance and go beyond the abilities of the human mind in the field of computation. The tasks carried out by data science are the very ones that Alan Turing identified as best suited to Al and for which humans cannot compete with machines. This is cause for concern in that "big data" a result of computing operations lack insight, emotions, creativity, purpose, outcomes, and generally a raison d'être - this is where humans are needed but education is focusing on what $\mathrm{Al}$ and $\mathrm{ML}$ do best - and leaving humans to figure out where they will fit in this new computationally simulated world.

\subsection{The Post-Covid World in Digital Time/Space}

The extreme impact of Covid on our daily lives brings insight into the nature of digitality as we witness the transformation of work in what we define as the real world suddenly changing radically in unprecedented ways fuelled by computing and $\mathrm{Al}$ converging with social and political unrest and an identity culture crisis. As public space and the public square is abandoned, new social movements converge seen mostly on screens worldwide leaving an immense lacuna of social interaction being replaced with social distancing. People taking refuge in their homes. Human communication, hijacked by Zoom and education moving online causing the digitalisation of the classroom, while theatres, museums, concert halls and most performance and sports venues are digitalised as well as they closed their doors to the public leaving no option but to see life through a screen positioning Human-Computer Interaction $(\mathrm{HCl})$ in a dominant position unsure of how limited human to human interaction will impact our sense of being human as we became more isolated, and fearful human encounters.

Computing and $\mathrm{Al}$ has moved to centre-stage simulating life's activities (Bowen et al. 2020). Technology developments over the past couple of years have enabled new digital horizons as what we believe to be uniquely human goes digital, from $\mathrm{Al}$ and digital senses to a wide range of robotic functions. Digital adoption was already trending upward pre-Covid but in ways allowing people to have choices and options about what to convert to digital, and clearly, as long as the pandemic lasts along with its empty public spaces, big tech has free reign to expand the current digital landscape into areas we thought were reserved for humans, and in this exceptional moment for digitality, the tech sector is ramping up the pace of digital innovation across platforms and networks, new apps, wearables, embedded technology and robotics. What seems most pressing is the rapid acceleration of remote work.

During these dramatic changes, culture itself is being reimagined creating fresh narratives reflecting the diversity of conversations and collaboration across the global digital ecosystem sparking growing social protest. These forces of digital change will only intensify, but there will be no turning back from the growing digitality of our daily lives. Increasingly, humans are emulating $\mathrm{Al}$ and robots, as human identity morphs to integrate physical and digital states of being while hoping there will be a place for them in this new world order.

As traditional jobs and legacy systems are replaced by $\mathrm{Al}$ systems and networks, how will humans reimagine themselves in the world of work. The world is no longer what we can see in the physical world, it's about the algorithms we cannot see making decisions for us. Having been in a state of isolation and fear for so long, we need to reconnect with our emotions, artistic expression and what it means to be human when $\mathrm{Al}$ and machines expand without limits transforming the physical world in a virtual 
state of digitality in which human and digital behaviour become inseparable.

\section{ENTERING THE DIGITAL FRONTIER}

\subsection{Art and Life at the Edge of Reality}

Covid has created the need to expand and rethink the definition of museums in the future, their purpose and ways of serving their communities. Just as it is no longer art for art's sake, it is no longer technology (AR, VR, etc.) for technology's sake. We are in a state of rapid change and a need for social justice perspectives, a levelling of the playing field and flattening of hierarchies. The museum landscape has just become much more complex and public expectations have shifted to allow for more participation, transparency, diversity, etc.

Street art and graffiti have given artists a place to keep human emotions and feelings in the public eye, when the public square seems empty and lifeless save for social protest and activism. These images and activities are digitally captured and then appear on computer screens and TVs across the globe. This is indeed powerful, and bears witness to recent events (Cascone 2020; Almino 2021).

\subsection{The Public Square - Foretelling the Future}

People outside museums are fighting for an equal place in society while museums are closed and empty. There is broad support for the "Black Lives Matter" (BLM) movement across generations and people of all colour seeking social justice and equity, an enduring message of the Covid crisis, now inextricably linked to the future of human society and communication. BLM has given cause to the diversification and reinterpretation of collections and the cultures they represent, spawning new narratives.

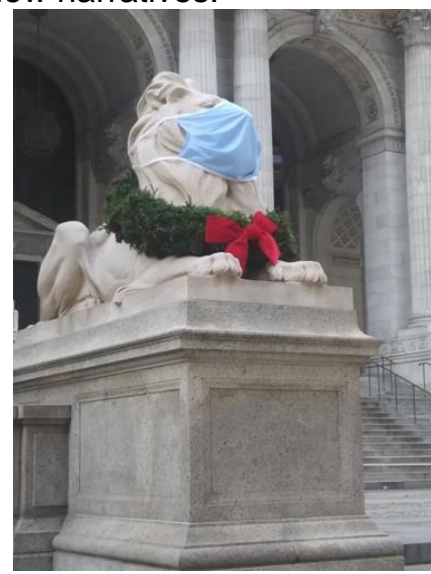

Figure 3: Lion statue at the 5th Ave entrance to New York Public Library with a Covid mask, December 2020. A symbol of the closure of libraries during the pandemic, raising new questions about the future of physical library collections by the public, shifting to digital collections. (Wikimedia Commons.)

\section{PRESENT TO FUTURE IN SEARCH OF A NEW ROAD}

\subsection{Museums, Libraries, and Archives}

Looking to the future from the vantage point of the present, a period of extreme disruption, during which Internet communication, computing, and $\mathrm{Al}$ are the key drivers of change in the social order, human behaviour and experience under the weight of Covid causing a surge of digitality in everyday life. For example, education is moving en masse to online, while shopping online has reached unprecedented levels of participation; e-books and other forms of digital information are holding sway among users.

At the same time, museums, libraries, and archives have been forced to close and move online leaving behind their traditional modes of operating in the physical museum for a virtual presence on the Internet. Thus, these institutions, especially museums, are scrambling to find alternative paths to financial sustainability. Leading recently interviewed museum directors pointed to greater engagement with community, immersive experiences and connecting with popular art such as Disney classics as possible paths forward; Katrina Sedgwick, director of Australian Centre for the Moving Image notes (Szanto 2021):

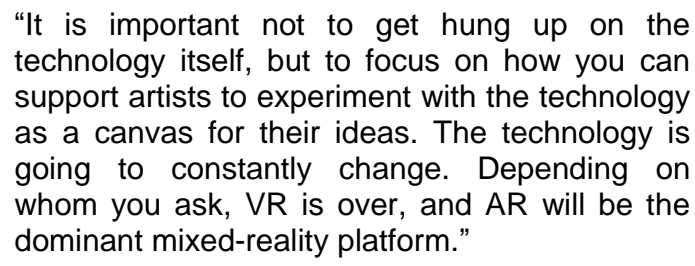

Although the directors raise insightful points, ultimately, new models that tie to financial sustainability and integrate museums onsite and online will be crucial. No doubt, the Internet will play a key role as museums expand their state of digitality across communication, user experience, interaction, outreach, and diversity. One approach might be partnerships with corporations such as Netflix and Disney as well as commercial sponsors of exhibitions. Museums might also consider feebased programs by diversifying education programs to include for credit degrees such as a master in museums drawing on their existing resources, collections and curators, particularly since over the past months museums have deepened their online presence and audience connections adding emerging technologies as 3D, AR, VR, MR, Al, etc., and post-Covid introducing experiential learning onsite.

Clearly there is a need for museums programs that prepare professionals to engage the social and curatorial challenges of the field as they strive to speak to more diverse audiences, that are 
especially effective in digital modes of communication, the modes du jour as the old print and text-dominated world fades (Giannini \& Bowen 2019d; Kinsella 2021).

We already know that the advance of digitality is unstoppable (Bowen \& Giannini 2014). However, there are critical choices to be made on how digital can be used most effectively and in ways that serve and enhance human experience, education and quality of life, and importantly, in ways that consider the roles and responsibilities reserved for human work and participation, that will more and more be a measure of human relationships with Al systems and robots.

\subsection{The Arts and Culture}

Digital art presents many opportunities for creativity by artists (Gompertz 2015, pp. 194-195). Many artists have resorted increasingly to online interaction with their associated public and clients, sometimes producing interesting interactive resources. For example, the artist Aphra Shemza produced a website (https://www.shemza.digital) in 2020 based on the art of her grandfather Anwa Shemza (1928-1985) that allows the production of digital artworks inspired by one of his paintings (see Figure 4).

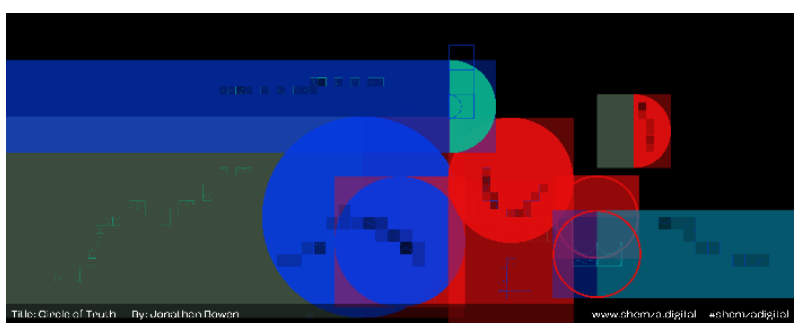

Figure 4: An artwork by Jonathan Bowen produced on the shemza. digital website.

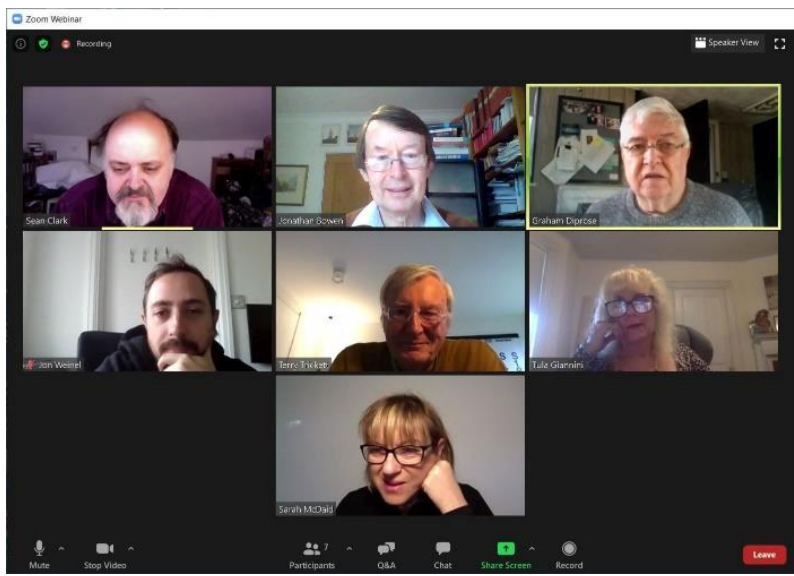

Figure 5: An EVA London organisation meeting in 2020

Overall, the Covid pandemic has had a fundamental effect on people's lives, increasing digitality with respect to work, social activities, shopping, culture, etc. The EVA London conference series itself has been radically affected compared to its physical past (Bowen 2020), with EVA London 2020 and its associated meetings held completely online via Zoom Webinar (see Figures 5 and 6).

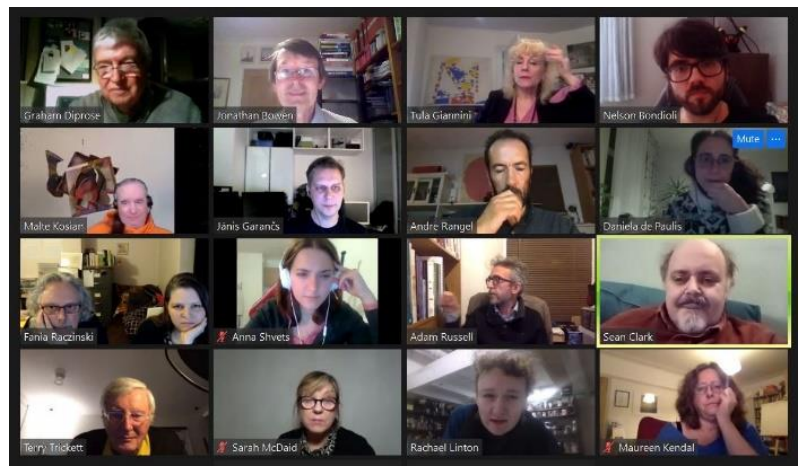

Figure 6: An EVA London 2020 session on Zoom.

\section{CONCLUSION}

\section{No going back (by T. Giannini)}

Covid
I hate you
Invader of life
Purveyor of death
Taking my last breath
of life in reality
No going back
to materiality
Digitality rules
fools our senses
Breaks down fences
Back to the trenches
of my postdigital life
Need healing
Reeling from lockdown
Love lost
At what cost

Alan Turing has continued to be an inspiration for digital culture long after his death (Bowen 2016; Bowen et al. 2018; Giannini \& Bowen 2017). There are similarities in his influence with that of Leonardo da Vinci (1452-1519), the much earlier Italian Renaissance polymath (Giannini \& Bowen 2020a; 2020b). In 2019, Turing won a BBC public vote for the greatest person of the $20^{\text {th }}$ century; in the televised final, Chris Packham gave an empathic and rousing tribute for Turing (Bowen 2019):

"Get your phones out of your pocket, and turn them on, and hold them up, just so that they can sparkle. In each of your hands, you hold a little bit of Alan Turing. He's with us when we wake up, he's with us when we go to bed at night, and he's with us when we talk to our loved ones. He's beautiful, isn't he, glistening in our darkest hour. You see, Alan Turing's legacy hasn't passed, he's not a relic of the 20th century, his gift to us is our future." 
The authors of this paper endorse this sentiment. Despite the negativity of issues such as fake news on social media, and the difficulties due to the pandemic, the authors look forward to a bright digital future and a positive legacy of Alan Turing.

\section{Acknowledgements}

This paper has taken inspiration from a recent book (Giannini \& Bowen 2019a) and previous EVA conference papers (Bowen \& Giannini 2014; Giannini \& Bowen 2017; 2018; 2019e; 2020a; 2020b; Bowen et al. 2020). Jonathan Bowen is grateful to Museophile Limited for financial support.

\section{REFERENCES}

Almino, E. W. (2021) How Cameras and Webcams have Helped us Bear Witness in 2020. Hyperallergic, 5 January. https://hyperallergic.com/612922/come-a-little-closer-uscroski-18th-street-arts-center/

Berry, M. (2017) Creating with Mobile Media. Palgrave Macmillan.

Bowen, J. P. (1995a) The Virtual Library of museums. In G. Day (ed.), Proc. Museum Collections and the Information Superhighway, 10 May 1995, Science Museum, London.

Bowen, J. P. (1995b) Collections of collections. Museums Journal, 95(8), pp. 24-25, August.

Bowen, J. P. (2016) Alan Turing: Virtuosity and visualisation. In Bowen et al. (2016), pp. 197-204. DOI: 10.14236/ewic/EVA2016.40

Bowen, J. P. (2017) Digital conservation and preservation: Whence and whither? In MATCONS 2017: Matter and Materials in/for Heritage Conservation, Craiova, Romania, September 2017, pp. 45-54.

Bowen J. P. (2019) The impact of Alan Turing: Formal methods and beyond. In: J. P. Bowen, Z. Liu, and Z. Zhang (eds.), Engineering Trustworthy Software Systems. SETSS 2018. Springer, Lecture Notes in Computer Science, vol. 11430, pp. 202-235. DOI: https://doi.org/10.1007/978-3030-17601-3 5

Bowen, J. P. (2020) A personal view of EVA London: Past, present, future. In Weinel et al. (2020), pp. 8-15. DOI: 10.14236/ewic/EVA2020.2

Bowen, J. P., Diprose, G., and Lambert, N. (eds.) (2016) EVA London 2016: Electronic Visualisation and the Arts. BCS, Electronic Workshops in Computing (eWiC). DOI: 10.14236/ewic/eva2016.0

Bowen, J. P., Diprose, G., and Lambert, N. (eds.) (2017) EVA London 2017: Electronic Visualisation and the Arts. BCS, Electronic Workshops in Computing (eWiC). DOI: 10.14236/ewic/eva2017.0

Bowen, J. P. and Giannini, T. (2014) Digitalism: The new realism? In K. Ng, J. P. Bowen, and S. McDaid (eds.), EVA London 2014: Electronic Visualisation and the Arts. BCS, eWiC, pp. 324-331. DOI: 10.14236/ewic/eva2014.38

Bowen, J. P. and Giannini, T. (2019) The Digital Future of Museums. In Giannini \& Bowen (2019a), chapter 28, pp. 551-577. DOI: $10.1007 / 978-3-319-97457-628$

Bowen, J. P., Giannini, T., Polmeer, G., Falconer, R., Miller, A. I., and Dunn, S. (2020) Computational culture and Al: Challenging human identity and curatorial practice. In Weinel et al. (2020), pp. 1-7. DOI: 10.14236/ewic/EVA2020.1
Bowen, J. P., Trickett, T., Green, J. B. A., and Lomas, A. (2018) Turing's genius - defining an apt microcosm. In Bowen et al. (2018), pp. 155-162. DOI: 10.14236/ewic/EVA2018.31

Bowen, J. P., Weinel, J., Diprose, G., and Lambert, N. (eds.) (2018) EVA London 2018: Electronic Visualisation and the Arts. BCS, Electronic Workshops in Computing (eWiC). DOI: 10.14236/ewic/eva2018.0

Brusaporci, S. (2018) Advanced mixed heritage: A visual turn through digitality and reality of architecture. International Journal of Computational Methods in Heritage Science, 2(1). DOI: $10.4018 /$ IJCMHS.2018010104

Cascone, S. (2020) Street Artists Around the World Captured a Turbulent Year in Real Time - See the Beautiful and Unforgettable Works of 2020 Here. Artnet News, 31 December 2020. https://news.artnet.com/art-world/street-art2020-1933692

Chau, C. (2017) Movement, Time, Technology, and Art. Springer, Series on Cultural Computing. DOI: 10.1007/978981-10-4705-3

Copeland, B. J., Bowen, J. P., Sprevak, M., Wilson, R. J., et al. (2017) The Turing Guide. Oxford University Press. https://en.wikipedia.org/wiki/The Turing Guide

Dasgupta, S. (2014) It Began with Babbage: The genesis of computer science. Oxford University Press.

Franklin, S. (2015) Control: Digitality as cultural logic. The MIT Press. https://mitpress.mit.edu/books/control

Florida, R. and Seman, M. (2020) Lost art: Measuring COVID-19's devastating impact on America's creative economy. The Brookings Institution, Washington, D.C., 11 August 2020. https://www.brookings.edu/research/lost-artmeasuring-covid-19s-devastating-impact-on-americascreative-economy/

Gaia, G., Boiano, S., Bowen, J. P., and Borda, A. (2020) Museum websites of the first wave: The rise of the virtual museum. In Weinel et al. (2020), pp. 24-31. DOI: 10.14236/ewic/EVA2020.4

Geroimenko, V. (ed.) (2019) Augmented Reality Games II: The gamification of education, medicine and art. Springer. DOI: $10.1007 / 978-3-030-15620-6$

Giannini, T. and Bowen, J.P. (2014) The Brooklyn Visual Heritage website: Brooklyn's museums and libraries collaborate for Project CHART. In MW2014: Museums and the Web 2014, Baltimore, USA, 2-5 April 2014. http://mw2014.museumsandtheweb.com/paper/thebrooklyn-visual-heritage-website/

Giannini, T. and Bowen, J. P. (2017) Life in code and digits: When Shannon met Turing. In Bowen et al. (2017), pp. 5158. DOI: 10.14236/ewic/EVA2017.9

Giannini, T. and Bowen, J. P. (2018) Of museums and digital culture: A landscape view. In Bowen et al. (2018), pp. 172-179. DOI: 10.14236/ewic/EVA2018.34

Giannini, T. and Bowen, J. P. (eds.) (2019a) Museums and Digital Culture: New perspectives and research. Springer, Series on Cultural Computing. DOI: $\quad \underline{10.1007 / 978-3-319-}$ 97457-6

Giannini, T. and Bowen, J. P. (2019b) Digital Culture. In Giannini \& Bowen (2019a), chapter 1, pp. 3-26. DOI: 10.1007/978-3-319-97457-6 1

Giannini, T. and Bowen, J. P. (2019c) Museums and Digitalism. In Giannini \& Bowen (2019a), chapter 2, pp. 2746. DOI: $10.1007 / 978-3-319-97457-62$

Giannini, T. and Bowen, J. P. (2019d) Transforming Education for Museum Professionals in the Digital Age. In Giannini \& Bowen (2019a), chapter 23, pp. 457-480. DOI: 10.1007/978-3-319-97457-6 23 
Giannini, T. and Bowen, J. P. (2019e) Art and activism at museums in a post-digital world. In Weinel et al. (2019), pp. 27-35. DOI: 10.14236/ewic/EVA2019.4

Giannini, T. and Bowen, J. P. (2020a) The digital Renaissance from da Vinci to Turing. In V. Cappellini et al. (eds.), EVA 2020 Florence Proceedings. DOI: 10.31235/osf.io/h5fm4

Giannini, T. and Bowen, J. P. (2020b) Computing the Future: Digital encounters in art and science when da Vinci met Turing. In Weinel et al. (2020), pp. 16-23. DOI: 10.14236/ewic/EVA2020.3

Gompertz, W. (2015) Think Like an Artist ... and lead a more creative, productive life. Penguin Books.

Hasson, R. (2019) Digitality, Virtual Reality and the 'empathy machine'. Digital Journalism, 8(2). DOI: 10.1080/21670811.2018.1517604

Hasson, R. (2020) The Condition of Digitality: A postmodern Marxism for the practice of digital life. University of Westminster Press. DOI: $10.16997 /$ book44

Hollings, C., Martin. U., and Rice, A. (2018) Ada Lovelace: The making of a computer scientist. Bodleian Library, University of Oxford.

loannides, M., Magnenat-Thalmann, N., and Papagiannakis, G. (eds.) (2017) Mixed Reality and Gamification for Cultural Heritage. Springer. DOI: 10.1007/978-3-319-49607-8

James, E. and Kearns, R. (2020) Linking therapeutic (is)landscapes, experiences of digitality and the quest for wellbeing. Wellbeing, Space and Society, 1. DOI: 10.1016/j.wss.2020.100010

Jandrić, P., Knox, J., Besley, T., Ryberg, T., Suoranta, J., and Hayes, S. (2018) Postdigital science and education. Educational Philosophy and Theory, 50(10), pp. 893-899. DOI: $10.1080 / 00131857.2018 .1454000$

King, H. (2015) Virtual Memory: Time-based art and the dream of digitality. Duke University Press.

Kinsella, E. (2021) 'We'd Love to Work with Netflix Again': Cash-Strapped Museums Looking for New Audiences are Increasingly doing Exhibits-for-Hire. Artnet News, 4 January 2021. https://news.artnet.com/art-world/its-a-deal-is-the-risein-museum-sponcon-linked-to-lockdown-1933514

Korte, M. (2020) The impact of the digital revolution on human brain and behavior: Where do we stand? Dialogues in Clinical Neuroscience, 22(2), pp. 101-111. DOI: 10.31887/DCNS.2020.22.2/mkorte

Lewis, G. (2007) The Wizard of Oz: Pay no attention. YouTube, 31 December. https://youtu.be/NZR64EF3OpA

Liu, Z., Bowen, J. P., Liu, B., Tyszberowicz, S., and Zhang T. (2020) Software abstractions and Human-Cyber-Physical Systems architecture modelling. In: J. P. Bowen, Z. Liu, and Z. Zhang (eds.), Engineering Trustworthy Software Systems. SETSS 2019. Springer, Lecture Notes in Computer Science, vol. 12154, pp. 159-219. DOI: 10.1007/978-3-030-55089$\underline{95}$

Mezaris, V., Niederée, C., and Logie, R. H. (eds.) (2018) Personal Multimedia Preservation: Remembering or forgetting images and video. Springer, Series on Cultural Computing. DOI: 10.1007/978-3-319-73465-1

Moore, M. and Tambini, D. (eds.) (2018) Digital Dominance: The power of Google, Amazon, Facebook, and Apple. Oxford University Press.

Nawotka, E. (2020) How the coronavirus will change book publishing, now and forever. Los Angeles Times, 25 March. https://www.latimes.com/entertainmentarts/books/story/2020-03-25/how-the-coronavirus-willchange-book-publishing-now-and-forever
Ovenden, R. (2020) The Digital Deluge. In Burning the Books: A history of knowledge under attack, chapter 13, pp. 197-223. John Murray.

Padua, S. (2015) The Thrilling Adventures of Lovelace and Babbage. Penguin Random House.

Peddie, J. (2017) Augmented Reality: Where we will all live. Springer. DOI: $10.1007 / 978-3-319-54502-8$

Peters, M. A. and Besley, T. (2019) Critical philosophy of the postdigital. Postdigital Science and Education, 1, pp. 29-42. DOI: $10.1007 / \mathrm{s} 42438-018-0004-9$

Rajan, A. (2020) How coronavirus infected publishing BBC News, Entertainment \& Arts, 16 April 2020. https://www.bbc.com/news/entertainment-arts-52299925

Ravetto-Biagioli, K. (2019) Digital Uncanny. Oxford University Press.

Schneegass, S. and Amft, O. (eds.) (2017) Smart Textiles: Fundamentals, design, and interaction. Springer, HumanComputer Interaction Series. DOI: 10.1007/978-3-31950124-6

Seevinck, J. (2017) Emergence in Interactive Art. Springer, Series on Cultural Computing. DOI: $\quad$ 10.1007/978-3-31945201-2

Statistica (2020) Time spent per day with digital versus traditional media in the United States from 2011 to 2020. https://www.statista.com/statistics/565628/time-spent-digitaltraditional-media-usa/

Szanto, A. (2021) What Is the Future of Museums? 7 Predictions from Max Hollein, Koyo Kouoh, Anne Pasternak, and Other Top Curators and Directors. Artnet News, 1 January 2021. https://news.artnet.com/art-world/future-ofmuseums-andras-szanto-1934142

Turing, A. M. (1936) On computable numbers with an application to the Entscheidungsproblem. Proceedings of the London Mathematical Society (2), 42(1), pp. 230-265. DOI: $10.1112 / \mathrm{plms} / \mathrm{s} 2-42.1 .230$

Vaidhyanathan, S. (2018) Anti-Social Media: How Facebook disconnects us and undermines democracy. Oxford University Press.

Vermeeren, A., Calvi, L., and Sabiescu. A. (eds.) (2018) Museum Experience Design: Crowds, ecosystems and novel technologies. Springer, Series on Cultural Computing. DOI: $10.1007 / 978-3-319-58550-5$

Wainwright, O. (2019) New York's high-rise jails: What could go wrong? The Guardian, 9 December 2019. https://www.thequardian.com/cities/2019/dec/09/new-yorkshigh-rise-prisons-what-could-go-wrong

Weinel, J., Bowen, J. P., Diprose, G., and Lambert, N. (eds.) (2019) EVA London 2019: Electronic Visualisation and the Arts. BCS, Electronic Workshops in Computing (eWiC). ScienceOpen. DOI: 10.14236/ewic/EVA2019.0

Weinel, J., Bowen, J. P., Diprose, G., and Lambert, N. (eds.) (2020) EVA London 2020: Electronic Visualisation and the Arts. BCS, Electronic Workshops in Computing (eWiC). ScienceOpen. DOI: 10.14236/ewic/EVA2020.0

Whatley, S., Cisneros, R. K., and Sabiescu, A. (eds.) (2018) Digital Echoes: Spaces for intangible and performancebased cultural heritage. Springer. DOI: 10.1007/978-3-31973817-8

Wieners, B. and Pescovitz, D. (1996) Reality Check. HardWired.

Wise, B. (2020) UF becomes first U.S. university to acquire cutting-edge NVIDIA DGX A100 system, advancing its artificial intelligence initiative. University of Florida, 14 May 2020. https://news.ufl.edu/2020/05/ 